\title{
Oxygenated germacranolides from Compositae and their taxonomic significance ${ }^{\dagger}$
}

\author{
Vivek Krishna, Kavita Natani and Pahup Singh* \\ Department of Chemistry, University of Rajasthan, Jaipur-302 004, India \\ E-mail : pahupsingh@yahoo.co.uk
}

Manuscript received 22 August 2003

\begin{abstract}
The chemistry of thirtysix new oxygenated germacranolides in addition to several known sesquiterpene lactones of other types isolated from the aerial parts of Vernonia arkansana, Mikania purpurascens, Inula cuspidata, Eremanthus crotonoides, Dicoma tomentosa, Dicoma anomala, Dicoma schinzii and Blainvillea acmella have been reviewed.
\end{abstract}

The germacranolides represent a large group of sesquiterpene lactones, derived from the germacrane skeleton. The suffix "olide" in their names refers to the lactone function in the molecule.

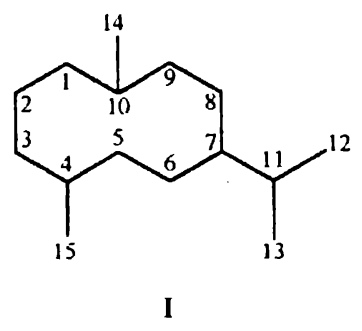

Germacrane (I) is a ten membered ring compound with two methyls and an isopropyl side chain. Considerable structural variety is recognized within this class of compounds, which is mainly due to the unique configurational and conformational features and the reactivity of the cyclodecadiene skeleton. Recent recognition of configurationally isomeric germacranolides has led to their reclassification into four subgroups, shown below, which are characterized by a cyclodecadiene skeleton with double bonds in the $\mathrm{C}-1,10$ and $\mathrm{C}-4,5$ positions.

Among the four subgroups, the majority represent germacrolides (IIa), although an increasing number of melampolides (IIb) and heliangolides (IIc) have been isolated. The smallest group, lately discovered, is represented by the cis, cis germacranolides (IId). It is not clear whether the biosynthesis of the four subgroups follows independent biogenetic pathways from the four possible configurationally isomeric farnesols or whether the configurational isomers are formed from the germacrolide skeleton by double bond isomerizations at a later stage of biosynthesis. The co-occurrence of more than one skeletal types in the same

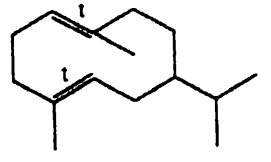

IIa Germacrolide

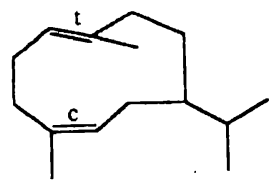

IIc Heliangolide

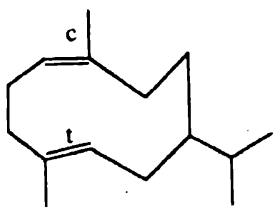

IIb Melampolide

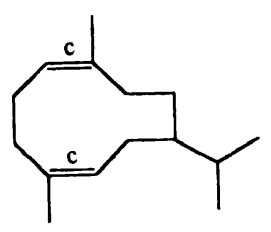

Ild cis,cis-Germacranolide plant species or genus and the fact that at least in the melampolide series all presently known compounds have an oxidized C-14, found either as aldehydes or as carboxylic acid derivatives (esters or lactones), could be an indication of interconversion from one to the other skeletal system during photochemical or spontaneous double bond isomerizations.

Further structural variations among the aforesaid groups of germacranolides involve the incorporation of an epoxy, furan, hydroxyl and/or ester moieties, or the lactone ring being cis or trans fused to $\mathrm{C}_{6}-\mathrm{C}_{7}$ or $\mathrm{C}_{8}-\mathrm{C}_{7}$ positions of carbocyclic skeleton. Sesquiterpene lactones generally occur as acetates or carry other ester side chains. Acids frequently involved in esterifications are of 4 and/or 5 carbon atoms, such as methacrylic (Meacr), isobutyric (iBu), tiglic (Tigl), angelic (Ang), $\alpha$-methylbutyric ( $\alpha$-MeBu), senecioic (Sen), isovaleric (iVal) acids or their hydroxy and/or acetoxy derivatives; the abbreviations used for the corresponding acyl groups are given within parentheses.

'Dedicated to Professor S. M. Mukherji. 
Besides typical NMR parameters, the ester groups generally display diagnostic mass spectral peaks. Commonly, the $\mathrm{M}-\mathrm{RCOOH}$ and/or $\mathrm{M}$-ketene are detected as reasonably strong peaks and the peak due to the acylium ion $\left(\mathrm{RCO}^{+}\right)$ frequently represents the base peak.

The nature of these sesquiterpene lactones varies from colourless oil to crystalline solids with high melting points. These are highly bitter, relatively stable and lypophylic constituents showing wide variety of physiological activities.

In this review, we present the results of structure elucidation of a germacranolide from Vernonia arkansana ${ }^{l}$, an epoxy germacranolide from Mikania purpurascens ${ }^{2}$, five esterified germacranolides from Inula cuspidata ${ }^{3}$, three furanoheliangolides from Eremanthus crotonoides $^{4}$, four melampolides and four germacranolides from Dicoma tomentosa ${ }^{5}$, four 7,8-germacranolides from Dicoma anomala $^{6}$, three germacranolides from Dicoma schinzii ${ }^{6}$, four germacranolides and seven acanthospermolides from Blainvillea acmella ${ }^{7}$, two known gemacranolides zoapatanolides A and B from B. latifolia ${ }^{8}$ and acetylenic germacranolides from Vernonia cotoneaster ${ }^{9}$.

Vernonia arkansana DC. has been investigated previously ${ }^{10,11}$. The reinvestigation of roots afforded costunolide 1 and the known guaianolides, while its aerial parts gave the glaucolide marginatin (heliangolide) 2 together with the corresponding new methacrylate $\mathbf{3}$. The structure of $\mathbf{3}$, $\mathrm{C}_{21} \mathrm{H}_{26} \mathrm{O}_{7}$ (HRMS), was clearly arrived from the ${ }^{1} \mathrm{H}$ NMR spectral data which were very much similar to that of marginatin $2^{11,12}$.
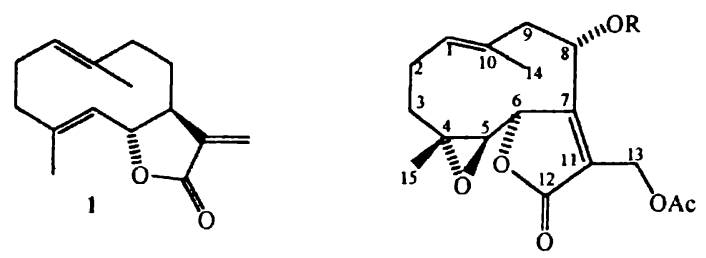

$$
\begin{aligned}
2 \mathrm{R} & =\text { Tigl } \\
3 \mathrm{R} & =\text { Meacr }
\end{aligned}
$$

The presence of methacrylate ester residue in 3 was evident by the appearance of signals at $\delta 5.67$ (dq) and 6.12 (brs) for vinylic protons and $\delta 1.92$ (brs) for the olefinic methyl group, respectively. It was characterized as 8-deacyl marginatin-methacrylate.

Mikania is a large genus and belongs to tribe Eupatorieae and subtribe Mikaniinae ${ }^{13}$. Some species of this genus afforded highly oxygenated lactones ${ }^{14}$, while others mainly give diterpenes of ent-kaurene types ${ }^{15}$. The aerial parts of Mikania purpurascens gave 5,10-epoxygermacranolide 4.

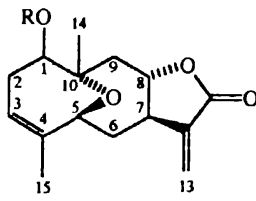

$4 \mathrm{R}=\mathrm{H}$

$5 \mathrm{R}=\mathrm{Ac}$

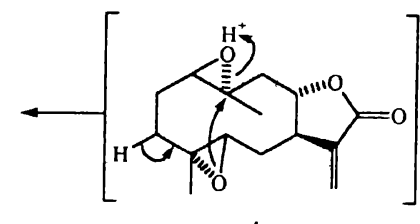

A
The structure of 4 was arrived from its spectral studies. The presence of a $\gamma$-lactone and a hydroxyl groups was assured from its IR spectrum while its molecular formula $\mathrm{C}_{15} \mathrm{H}_{20} \mathrm{O}_{4}$ indicated an additional oxygen function. $\mathrm{C}-5 \mathrm{H} \alpha$ gave a broad doublet at $\delta 4.45$ indicating the presence of 5,10 -oxygen bridge. This compound is most probably formed via diepoxide A. Germacranolides with 5,10-oxygen bridge have so far only been reported from Liatris species ${ }^{16}$. However, these compounds are 6,12-lactones. The compound 4 was named as purpurascenolide.

So far the results of chemical investigation of Inula species (tribe Inuleae) indicated the presence of simple sesquiterpene lactones ${ }^{17}$. Some more complex ones have been reported from Inula eupatorioides ${ }^{18}$. The investigation of the aerial parts of Inual cuspidata C.B. Clarke afforded $1 \beta$-hydroxy-1,10-dihydro-10,14 dehydrogermacrene D alongwith five new germacranolides 6-10. These lactones were separated by HPLC (reverse phase) from polar fractions.

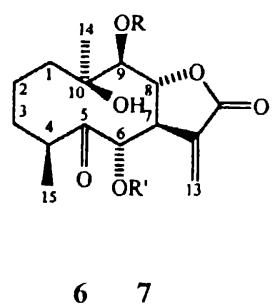

$$
\begin{array}{llll}
R & \text { iBu } & \text { iBu } & \text { iVal, MeBu } \\
\mathrm{R}^{\prime} & \text { iBu } & \text { iVal, MeBu } & \text { iBu }
\end{array}
$$

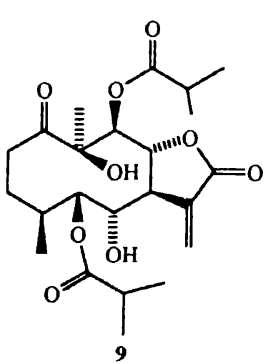

Their ${ }^{1}$ H NMR data clearly showed that all compounds were methylene lactones. The data of $\mathbf{6}$ and $\mathbf{1 0}$ showed the presence of 8,12-lactone moiety. Incaspitolide-A (6) obviously was a diisobutyrate with an additional hydroxy and a keto group. Careful spin decoupling established the sequence of protons. The stereochemistry was deduced from the couplings observed and from inspection of models. As both $J_{6,7}$ and $J_{8,9}$ were large, only a trans-orientation at C-6-C-9 was likely. The conformation is in agreement with the couplings of $\mathrm{H}-6-\mathrm{H}-9$, those of $\mathrm{H}-4$ required a $\beta$-position of the 4-methyl group. As the ${ }^{1} \mathrm{H}$ NMR spectrum indicated a 
Krishna et al. : Oxygenated germacranolides from Compositae etc.
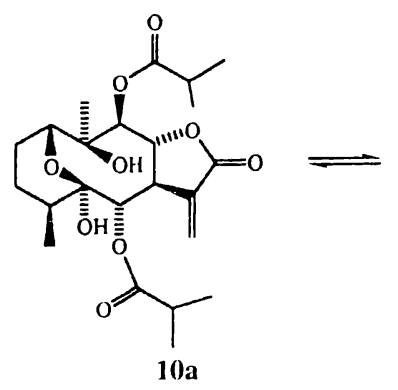

relatively rigid conformation, a hydrogen bridge between 10$\mathrm{OH}$ and the keto group was likely. This however, required a $10 \beta$-hydroxy group. Therefore the stereochemistry at C-4 and $C-7-C-10$ was the same as that of ineupatorolide- $A$, where the configuration is established by $\mathrm{X}$-ray ${ }^{18}$. The ${ }^{1} \mathrm{H}$ NMR data of the mixture of incaspitolide-B and $\mathrm{C}$ ( $\mathbf{7}$ and $\mathbf{8}$ ) clearly showed that these compounds only differed from 6 by ester residues. The typical signals of isobutyrates, isovalerate and 2-methylbutyrates clearly could be identified. However, since separation was not possible, hence no decision can be given regarding the locations of the different ester groups. As the signals of the tertiary protons of the isobutyrate moieties were different in the spectrum of $\mathbf{6}$, more than two compounds probably were present. The ${ }^{1} \mathrm{H}$ NMR data of incaspitolide-D (9) indicated that the substitution pattern was different from that of 6 . Spin decoupling using the H-7 signal as the point of departure established the whole sequence H-2-H-9. The position of the ester groups was deduced from the chemical shifts, as the signal of H-6 was at higher field than that in the spectrum of $\mathbf{6}$ and, therefore, a free hydroxyl at C-6 was very likely. The presence of a keto group at C-1 was supported by the chemical shifts of $\mathrm{H}-2$ and their couplings. The stereochemistry at C-4 and C-10 is likely to be the same as that in 6-8. Incaspitolide-E (10a) on acetylation afforded the monoacetate 10c and the diacetate 10d. The ${ }^{1} \mathrm{H}$ NMR data showed that 10c and 10d obviously were secondary acetates with a keto group at C-5, while the data of 10a indicated that the keto group was masked as the $\mathrm{H}-4$ signal was at much higher fields. Furthermore, the H-l signal was a sharp double doublet, unusual for a proton near a hydroxy group. Therefore the presence of a hemi-ketal was very likely, which, however, could be in equilibrium with ketone 10b, and could be shifted by acetylation. The ${ }^{1} \mathrm{H}$ NMR data were in good agreement with this assumption. Those of $10 \mathrm{c}$ clearly showed that the substitution at $\mathrm{C}-4-\mathrm{C}-10$ was the same as in 6 . The additional acetoxy group could be placed only at $\mathrm{C}-1$ as the corresponding signal of the proton under the acetoxy group was a clear double doublet. The model showed that the hydrogen bond between

the 10-hydroxy and the keto group was likely. Then, however, only an $\alpha$-orientated hydroxy would agree with the couplings observed. The dihedral angles would be in good agreement with the couplings observed for the other signals. Inspection of a model of $\mathbf{1 0 a}$ also showed that the observed couplings would agree with the proposed stereochemistry. In the spectrum of 10d the downfield shift of $\mathrm{H}-14$ clearly indicated that the second acetoxy group was at $\mathrm{C}-10$. The coupling of $\mathrm{H}-\mathrm{l}$ again was altered, indicating that the conformation was changed, probably due to the missing hydrogen bridge. At elevated temperature in the spectrum of $10 \mathrm{c}$ the $\mathrm{H}-\mathrm{I}$ couplings were close to those in 10d, showing that the hydrogen bridge may be very weak. Consequently, also the chemical shifts in the spectrum of $10 \mathrm{c}$ at higher temperature were altered.

The investigation of the aerial parts of Eremanthus crotonoides DC. afforded, in addition to known sesquiterpene lactones 11-16, three new furanoheliangolides 17-19. The known sesquiterpene lactones included three eremantholides 11-13 and three furanoheliangolides 14-16.
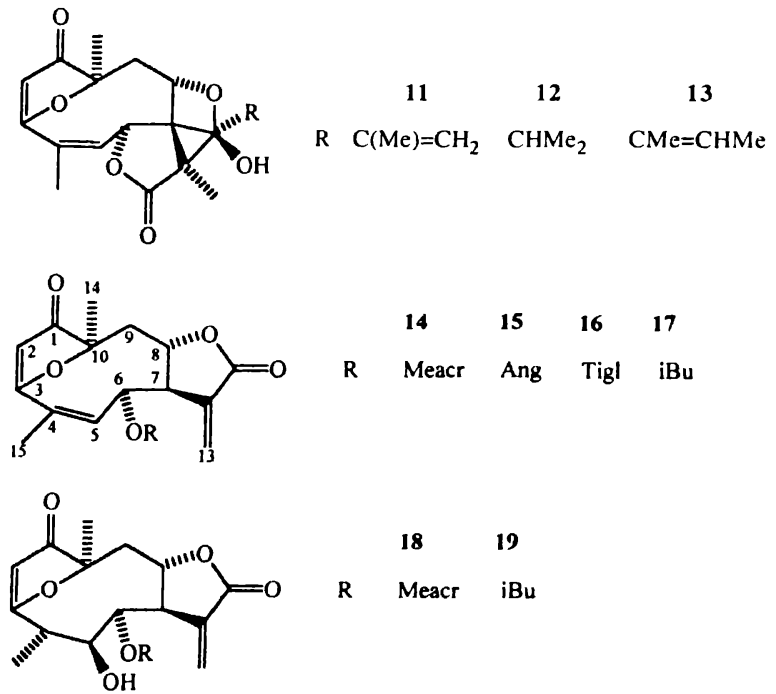

The structure of 17 was deduced from the ${ }^{1} \mathrm{H}$ NMR spectral data, which were similar to those of $14-16^{19,20}$, only the signals of the ester group being replaced by those of the isobutyrate. The other signals were slightly shifted when compared with those of the unsaturated esters. The lactones 18 and 19 again differed only in the nature of the ester groups. The molecular formula of 18 was $\mathrm{C}_{19} \mathrm{H}_{24} \mathrm{O}_{7}$. All oxygen functions were deduced from the ${ }^{1} \mathrm{H}$ NMR spectrum. In addition to signals of a methylene lactone, of a furanone moiety and a methacrylate, a downfield double doublet was present, which was separated from a second signal only in deuteriobenzene. Spin decoupling 
showed that a hydroxyl group was at C-5, since an irradiation of the corresponding signal the double doublet at $\delta 4.40$ collapsed to a doublet and a double doublet quartet (separated from a second signal only in deuterobenzene) to a broadened quartet. The latter further showed allylic coupling with $\mathrm{H}-2$, typical in cases when a $4 \beta$-proton is present ${ }^{20}$. The observed couplings of $\mathrm{H}-5$, therefore, required a $\beta$-position of the hydroxyl group. Further decoupling led to the assignment of $\mathrm{H}-7$ through H-9. The H-7 signal was easily assigned, since its irradiation collapsed the $\mathrm{H}-13$ signals to singlets and those of H-6 to a doublet. The presence of an 8,12-lactone was deduced by comparing the corresponding signals with those of similar lactones. Accordingly, 18 was the 4(15)dihydroderivative of a goyazensanolide isolated from a Vanillosmopsis species $^{21}$.

Previous investigations of Dicoma species (tribe Mutisieae, subtribe Gochanatiinae) have shown that 14,15oxygenated germacranolides may be typical for this genus $^{22,5}$. An investigation of the aerial parts of Dicoma tomentosa afforded urospermal-A (20), four new melampolides (21-24) and four germacranolides (25-28) together with $11 \beta, 13$-dihydroderivative $(29)^{23}$ of urospermal-A.
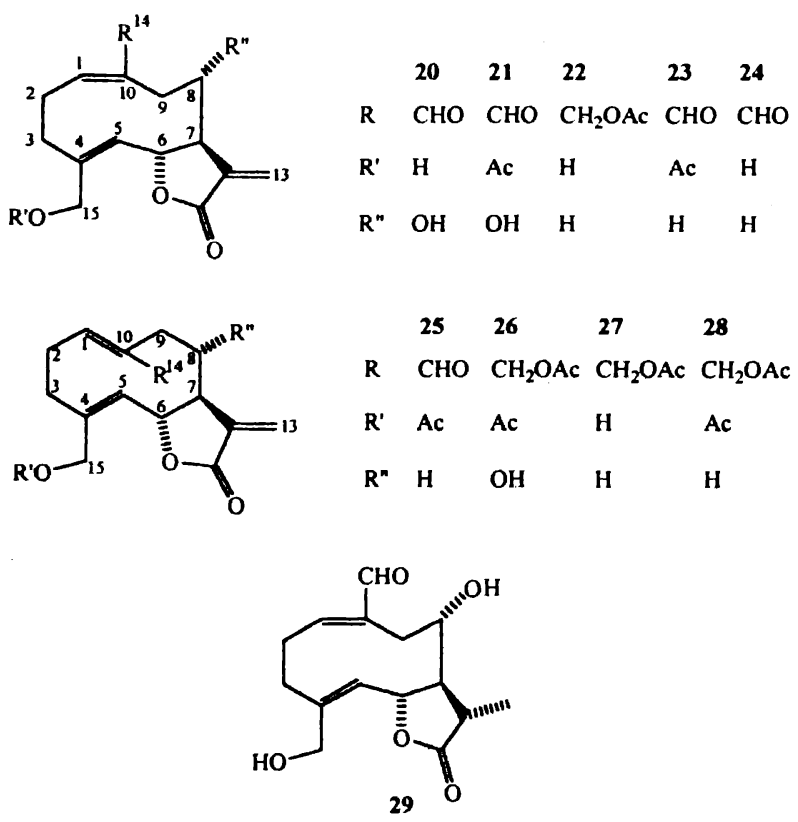

The structure of 21 followed from the ${ }^{1} \mathrm{H}$ NMR spectral data, which were close to those of 20 . As expected, the H-15 signals were shifted to downfield. The spectra of 27 and 28 showed that we were dealing with the mono and diacetate of albicolide. All signals in the spectrum of $\mathbf{2 8}$ were assigned by spin decoupling. When the spectrum of 22 was compared with that of 27 , the difference in the configuration of the 1,10-double bond became apparent. The downfield shift of the $\mathrm{H}-\mathrm{l}$ signal in the spectrum of 22, if compared with the H-l shift of 27 , supported a cis1,10 -double bond. The same is true in the spectrum of a diacetate, isolated previously from a Dicoma species $^{22}$. The configuration of the 1,10-double bond has to be changed to 1,10 -cis. The spectra of $\mathbf{2 3}$ and $\mathbf{2 4}$ showed that these lactones only differed at $\mathrm{C}-15$, the former being an acetate and the latter the corresponding hydroxy compound. The cis configuration of the 1,10-double bond followed from the chemical shift of $\mathrm{H}-14$. The ${ }^{1} \mathrm{H}$ NMR spectrum of 25 showed that this lactone was the 1,10-trans isomer of $\mathbf{2 3}$, as indicated by the chemical shift of H-14. The spectral data of 26 showed that this lactone was the $8 \alpha$-hydroxy derivative of 28 . As is usual in the $8 \alpha$-hydroxy germacranolides the $\mathrm{H}-13^{\prime}$ signal was shifted downfield and a coupling $J_{13,13^{\prime}}$ was visible. Also $\mathrm{H}-7$ was slightly deshielded by the 8 -hydroxy group. The aerial parts of Dicoma anomala Willd. afforded germacrene D and four new germacran-8,12-olides (30-33). All these lactones were 15-hydroxy-14-acetoxyger- macranolides with one addi-

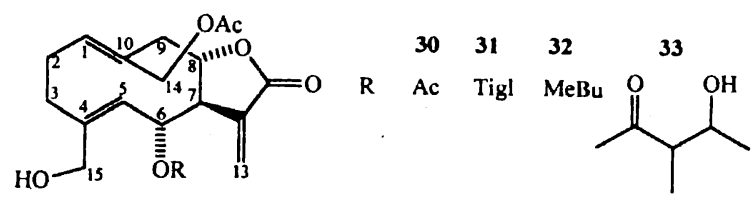

tional ester group. The nature of the ester functions followed from their typical signals. The lactone 33 was a 3hydroxy-2-methyl butyrate, as could be deduced from the doublet quartets at $\delta 2.45$ and 3.90 as well as from the two doublets at $\delta 1.26$ and 1.18 . The flexibility of the ring system and the couplings $J_{7,8}$ indicated the presence of 8,12lactones, while the chemical shifts of $\mathrm{H}-1$ and $\mathrm{H}-5$ required trans-double bonds. The $\alpha$-orientation of the ester groups followed from the couplings $J_{5,6}$ and $J_{6,7}$. The aerial parts of Dicoma schinzii O. Hoffm. afforded three new germacranolides (34-36) closely related to albicolide ${ }^{24}$.
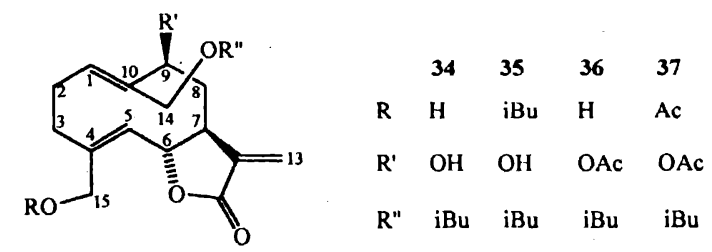

The structure of $\mathbf{3 4}$ followed from its ${ }^{1} \mathrm{H}$ NMR spectrum. Irradiation at $\delta 2.76$ showed that the signal was that of $\mathrm{H}-7$ as the typical methylene lactone doublets collapsed to singlets, the double doublet at $\delta 4.76$ to a doublet and the three fold doublets at $\delta 1.75$ and 2.34 to double doublets. Further spin decoupling allowed the as- 
Krishna et al. : Oxygenated germacranolides from Compositae etc.

signment of all signals. The stereochemistry of C-9 followed from the couplings observed, while the relative position of the isobutyrate residue followed from the chemical shifts of $\mathrm{H}-14$. The ${ }^{1} \mathrm{H}$ NMR spectral data of 35 were close to those of 34 . However, the signals of $\mathrm{H}-15$ were shifted downfield and signals of an additional isobutyrate residue were visible. Furthermore, a small shift of the H-14 signals indicated the usual conformation of germacranolides with both C-14 and C-15 above the plane. Compound 36 was a germacranolide with an acetate group. The ${ }^{1} \mathrm{H}$ NMR spectral data of $\mathbf{3 6}$ differed from those of $\mathbf{3 4}$ in the chemical shift of $\mathrm{H}-9$ indicating that the acetate was at $\mathrm{C}-9$. Furthermore, the $\mathrm{H}-\mathrm{l}$ signal was shifted downfield by $\delta 0.25$, which could be an indication of a 1,10-cis-double bond. However, acetylation of 34 afforded the diacetate 37 , where the $\mathrm{H}-1$ signal showed nearly the same chemical shift, showing that the downfield shift was due to the effect of the $9 \beta$-acetoxy group. As partial saponification of $\mathbf{3 6}$ was not successful, the relative position of the isobutyrate group could not be established. The proposed position seemed to be likely as all the other esters had a $\mathrm{C}_{4}$-ester group at C-14.

The chemistry of the genus Dicoma showed that highly oxygenated germacranolides, especially those with $\mathrm{O}$-functions at $\mathrm{C}-14$ and $\mathrm{C}-15$, may be typical and perhaps for the subtribe as similar lactones have been isolated from Actinoseris $^{23}$, Cnicothamnus ${ }^{25}$, Gochnatia ${ }^{26}$ and Wunderlichia $^{23}$, while from Pertya ${ }^{27}$ guaianolides were reported.

The genus Blainvillea (tribe Heliantheae) is placed in the subtribe Ecliptinae ${ }^{28,29}$. So far the chemistry of only one species has been studied ${ }^{30}$. The isolation of acanthospermolides was of taxonomic interest as this type of sesquiterpene lactones had not been observed previously in any genus of the subtribe Ecliptinae. The investigation of the aerial parts of Blainvillea acmella $\mathrm{L}$. afforded four new germacranolides 38-41 related to ovatifolin and seven new acanthospermolides $\mathbf{4 2 - 4 8}$ along with desacetylovatifolin (50), desacylgrazielic acid tiglate (51) and $8 \beta$-[2-methylbutyryloxy]-9 $\beta$-hydroxy-14-oxo-acanthospermolide (52).

The structure of 38 was deduced from its ${ }^{1} \mathrm{H}$ NMR spectrum which was close to that of ovatifolin $(49)^{31}$. However, the presence of an additional oxygen function was obvious as the pair of double doublets (H-9) were replaced by a doublet at $\delta 4.40$. Furthermore, the H-8 signal was shifted downfield compared to the corresponding shift in the spectrum of ovatifolin. Typical signals of a 2-methylbutyrate indicated that this was the ester at C-8. The configurations at C-8 and C-9 followed from the small
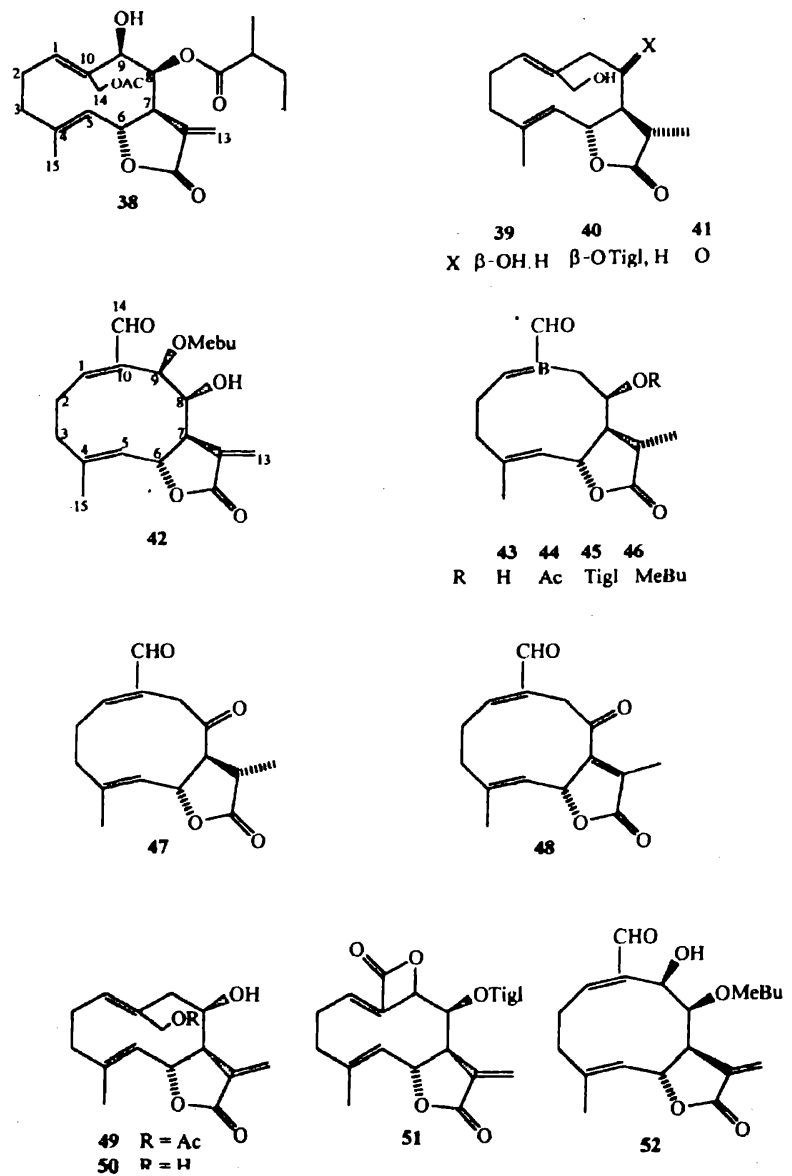

couplings which only agreed with a $\beta$-oriented oxygen function. The molecular formula of $39\left(\mathrm{C}_{15} \mathrm{H}_{22} \mathrm{O}_{4}\right)$ together with its IR spectrum indicated the presence of a dihydroxylactone. The ${ }^{1} \mathrm{H}$ NMR spectrum showed some similarities to that of desacetylovatifolin $(\mathbf{5 0})^{32}$. However, the absence of the exomethylene double bond was conspicuous. The characteristic signals of these protons were replaced by a methyl doublet and a double quartet which could be assigned by spin decoupling to $\mathrm{H}-11$. The coupling of the latter clearly showed an $\alpha$-orientated C-11 methyl group. The ${ }^{1} \mathrm{H}$ NMR spectrum of $\mathbf{4 0}$ was close to that of 39. The presence of the corresponding tiglate followed from the typical ${ }^{1} \mathrm{H}$ NMR signals and the observed downfield shift of the $\mathrm{H}-8$ signal. Thus $\mathbf{4 0}$ was the 8-Otiglate of 39 . The ${ }^{1} \mathrm{H}$ NMR spectrum of $\mathbf{4 1}$ differed somewhat from that of $\mathbf{3 9}$ though many signals were similar. The absence of an H-8 signal together with a new pair of doublets below $\delta 3$ clearly indicated a carbonyl group at $\mathrm{C}-8$. All this agreed with the presence of desacetoxy$11 \beta, 13$-dihydroovatifolin-8-one. Though lactone $\mathbf{4 2}$ gave no molecular ion the molecular formula could be deduced 
from the presence of the $\left[\mathrm{M}-\mathrm{RCO}_{2} \mathrm{H}\right]^{+}$and the acyl $(\mathrm{m} / \mathrm{z}$ 85 ) ions in the mass spectrum and the presence of a 2 methylbutyrate group according to the ${ }^{1} \mathrm{H}$ NMR spectrum. The other ${ }^{1} \mathrm{H}$ NMR spectral data strongly indicated that $\mathbf{4 2}$ was an isomer of $\mathbf{5 2} 2^{30}$. As could be deduced from the chemical shifts of $\mathrm{H}-8$ and $\mathrm{H}-9, \mathbf{4 2}$ and $\mathbf{5 2}$ differed only in the position of the ester residue.

The ${ }^{1} \mathrm{H}$ NMR spectra of $\mathbf{4 3 - 4 6}$ were in part very similar. The compounds $\mathbf{4 4 - 4 6}$ differed from each other only in the nature of the ester residue, which had to be placed at $\mathrm{C}-8$ on the basis of spin decoupling. The typical ester signals showed that 44 was the acetate, 45 the tiglate and 46 the 2-methylbutyrate of 43 . The signals of 43 were in part very close to those of $\mathbf{4 2}$. However, the absence of an oxygen function at C-9 led to the appearance of a pair of three fold doublets at $\delta 2.62$ and 2.00. On the other basis of models it was clear that the first signal was that of $\mathrm{H}-9 \alpha$ as in 42, a $\mathbf{W}$-coupling was observed between that proton $(\mathrm{H}-9 \alpha)$ and $\mathrm{H}-14$. Of course the absence of an ester group in $\mathbf{4 3}$ caused a considerable upfield shift of the signal of $\mathrm{H}-8$. The ${ }^{1} \mathrm{H}$ NMR spectrum of 47 showed similarities to that of $\mathbf{4 3}$. However, in addition to some shift differences, the absence of an $\mathrm{H}-8$ signal and the downfield shifts of the signals of $\mathrm{H}-7$ and $\mathrm{H}-9$ showed that the corresponding 8-keto derivative was present. The ${ }^{1} \mathrm{H}$ NMR spectrum of $\mathbf{4 8}$, whose molecular formula had two hydrogens less than that of 47 , showed the presence of an olefinic methyl $(\delta 1.96 \mathrm{~d})$ while no signals for $\mathrm{H}-7, \mathrm{H}-8$ and $\mathrm{H}-11$ were observed. As however, the remaining signals were close to those of 47 , the presence of the 7,11-dehydro derivative of the latter could be deduced.

The isolation of several acanthospermolides from Blainvillea acmella again indicates that these compounds may be characteristic for the genus. So far, such sesquiterpene lactones with an aldehyde group at $\mathrm{C}-10$ and a $8 \beta$-oxygen function have been reported from Acanthospermum $^{33,34}$, Smallanthus ${ }^{35}$, Siegesbeckia ${ }^{36}$ and Ichthyothere $^{37}$, while from Melampodium ${ }^{38}$, Tetragonotheca ${ }^{39}$ and Enhydra ${ }^{40}$ similar lactones with an ester group at $\mathrm{C}-10$ have been isolated. The co-occurrence of acanthospermolides and ovatifolin derivatives in Blainvillea is an indication that enzymatic oxidation of the hydroxy group of C-14 may be accompanied by isomerization of the 1(10)-double bond. If this is true Blainvillea may be related to Podanthus, which is also placed in the subtribe Ecliptinae where lactones like $\mathbf{3 8}$ are present.

\section{Acknowledgement}

The authors remain grateful to (Late) Prof. F. Bohlmann, Berlin, Germany, Prof. K. C. Joshi for helpful suggestions and recording high field ${ }^{1} \mathrm{H}$ NMR, high resolution mass and nOe spectra. Authors also thank the U.G.C., New Delhi, for financial support.

\section{References}

1. F. Bohlmann, Pahup Singh, N. Borthakur and J. Jakupovic, Phytochemistry, 1981, 20, 2379.

2. F. Boh!mann, Pahup Singh, J. Jakupovic, H. Robinson and R. M. King, Phytochemistry, 1982, 21, 705.

3. F. Bohlmann, Pahup Singh and J. Jakupovic, Phytochemistry, 1982, 21. 157.

4. F. Bohlmann, Pahup Singh, C. Zdero, A. Ruhe, R. M. King and H. Robinson, Phytochemistry, 1982, 21, 1669.

5. F. Bohlmann, Pahup Singh and J. Jakupovic, Phytochemistry, 1982, 21, 2122.

6. F. Bohlmann, Pahup Singh and J. Jakupovic, Phytochemistry, 1982, 21, 2029.

7. Pahup Singh, A. K. Sharma, K. C. Joshi, J. Jakupovic and F. Bohlmann, Phytochemistry, 1985, 24, 2023.

8. Pahup Singh, Reruka Jain and Vivek Krishna, Natural Product Sciences, 1998, 4, 42.

9. Vivek Krishna, Renuka Jain and Pahup Singh, Journal of Medicinal and Aromatic Plant Sciences, 1998, 20, 417.

10. F. Bohlmann, J. Jakupovic, R. K. Gupta, R. M. King and H. Robinson, Phytochemistry, 1981, 20, 473.

11. Z. H. Abdel-Baset, L. Southwide, W. G. Padolina, H. Yoshioka, T. J. Mabry and S. B. Jones, Phytochemistry, 1971, 10, 2201.

12. W. G. Padolina, N. Nakatoni, H. Yoshioka, T. J. Mabry and S. A. Monti, Phytochemistry, 1974, 13, 2225.

13. R. M. King and H. Robinson, Phytologia, 1980, 46, 446.

14. W. Herz, P. S. Subramaniam, K. Murari, N. Dennis and J. F. Blount, J. Org. Chem., 1977, 42, 1720.

15. F. Bohlmann, A. Adler, A. Schuster, R. K. Gupta, R. M. King and H. Robinson, Phytochemistry, 1981, 20, 1899.

16. W. Herz, I. Wahlberg, C. S. Stevens and P. S. Kalyanaraman, Phytochemistry, 1975, 14, 1803.

17. N. H. Fischer, E. J. Olivier and H. D. Fischer, Fortschr. Chem. Org. Naturst., 1979, 38, 47.

18. R. N. Baruah, R. P. Sharma, G. Thyagarajan, W. Herz and S. V. Govindan, J. Org. Chem., 1980, 45, 4838.

19. F. Bohlmann, C. Zdero, R. M. King and H. Robinson, Phytochemistry, 1980, 19, 2663.

20. F. Bohlmann, C. Zdero, H. Robinson and R. M. King, Phytochemistry, 1980, 19, 2381.

21. F. Bohlmann, C. Zdero, H. Robinson and R. M. King, Phytochemistry, 1981, 20, 731.

22. F. Bohlmann and N. Le Van, Phytochemistry, 1978, 17, 570 . 


\section{Krishna et al. : Oxygenated germacranolides from Compositae etc.}

23. F. Bohlmann, C. Zdero, H. Robinson and R. M. King, Phytochemistry, 1981, 20, 1631.

24. M. Suchy, Z. Samek, V. Herout and F. Sorm, Collect. Czech. Chem. Commun., 1967, 32, 3924.

25. F. Bohlmann and C. Zdero, Phytochemistry, 1979, 18, 95.

26. F. Bohlmann, J. Jakupovic, H. Robinson and R. M. King, Phytochemistry, 1981, 20, 109.

27. S. Nagumo, K. Izawa, K. Hagahiyama and M. Nagai, Yakugaku Zasshi, 1980, 100, 427.

28. T. F. Stuessy in 'The Biology and Chemistry of the Compositae', eds. V. H. Heywood, J. B. Harborne and B. L. Turner, Academic Press, London, 1977, p. 268.

29. H. Robinson, Smithsonian Contrib. Botany, 1981, 51, 1.

30. F. Bohlmann, J. Ziesche, R. M. King and H. Robinson, Phytochemistry, 1981, 20, 263.

31. S. Gnacco, J. P. Poyser, M. Silva, P. G. Sammes and T. W. Tyler, Phytochemistry, 1973, 12, 2469.
32. M. Hoeneisen, M. Silva and F. Bohlmann, Phytochemistry, 1980, 19, 2765.

33. W. Herz and P. S. Kalyanaraman, Phytochemistry, 1975, 14, 1664 .

34. F. Bohlmann, G. Schmeda-Hirschmann and J. Jakupovic, Planta Medica, 1984, 37, 37.

35. F. Bohlmann, J. Ziesche, R. M. King and H. Robinson, Phytochemistry, 1980, 19, 973.

36. R. N. Baruah, R. P. Sharma, G. Thyagarajan, W. Herz and S. V. Govindan, Phytochemistry, 1980, 19, 323.

37. F. Bohlmann, J. Jakupovic, A. Schuster, R. M. King and H. Robinson, Phytochemistry, 1982, 21, 2317.

38. A. J. Malcolm, J. F. Carpenter, F. R. Fronczek and N. H. Fischer, Phytochemistry, 1983, 22, 2759.

39. L. Quijano, E. J. Olivier and N. H. Fischer, Phytochemistry, 1980, 19, 1485.

40. F. Bohlmann, M. Ahmed, H. Robinson and R. M. King, Phytochemistry, 1982, 21, 1675. 
